\title{
Peertechz
}
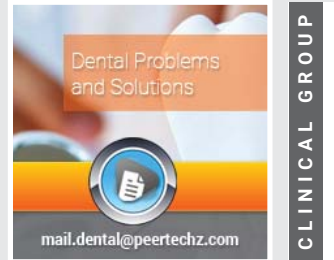

Research Article

\section{Effect of the Tiny Dentist game on 4-10 years old children's anxiety compared with Tell- Show-Do method: A clinical trial}

Received: 16 March, 2021

Accepted: 12 April, 2021

Published: 15 April, 2021

*Corresponding author: Amirreza Tahersoltani, DDS, School of Dentistry, Tehran University of Medical Sciences, Tehran, Iran, E-mail: a.reza.t.soltani@gmail.com

Keywords: Anxiety; Video game; Child

https://www.peertechzpublications.com

\section{Check for updates}

\section{Amirreza Tahersoltani ${ }^{1 *}$, Alireza Heidari ${ }^{2}$, Sara Ghadimi ${ }^{3}$ and Ahmad Reza Shamshiri ${ }^{4}$}

${ }^{1}$ School of Dentistry, Tehran University of Medical Sciences, Tehran, Iran

${ }^{2}$ Associate Professor of Pedodontics Department, School of Dentistry, Tehran University of Medical Science, Tehran, Iran

${ }^{3}$ Laser Research Center of Dentistry, Department of Pediatric Dentistry, Tehran University of Medical Sciences, Tehran, Iran

${ }^{4}$ Research Center for Caries Prevention, Dental Research Institute, Department of Community Oral Health, School of Dentistry, Tehran University of Medical Sciences, Tehran, Iran

\section{Abstract \\ Background: Tell-show-do is the gold standard for children's anxiety and behavior control. However, there are other techniques, including video games, which can also be efficient.}

Aim: To evaluate the effect of a dentistry smartphone game on children's anxiety on a treatment session using two scales in comparison with the conventional tellshow-do method.

Design: In this randomized clinical trial, children were divided into two groups with coin-flipping. They were taken to the unit and the pulse-oximeter was attached to their fingers to measure their heart rate. Then the techniques were applied to them regarding their group. The intervention group played with the game instead of tell-showdo, which the comparison group received. The procedure was filmed except for the intervention phase. After treatment, children were asked about their tolerated pain with the Wong-Baker index. Finally, two pediatric dentistry professors evaluated recorded films for children's anxiety by the Venham scale.

Results: A total of 85 children enrolled in the tell-show-do group and 58 in the game group. The game group marks were significantly ( $\mathrm{p} \leq 0.001)$ lower than the tellshow-do group marks in mean Venham scale $(1.25 \pm 0.74$ vs $1.98 \pm 1.04)$, mean heart rate during treatment $(105.22 \pm 8.22$ vs $111.35 \pm 13.15)$, heart rate difference in the intervention phase $(-16.43 \pm 20.06$ vs $0.47 \pm 23.58)$ and heart rate difference in the injection phase $(7.26 \pm 17.86$ vs $22.24 \pm 18.05)$. The pre-injection heart rate data was not significant $(p=0.11)$

Conclusion: It seems that the video game method has appropriate efficiency for anxiety control compared with the tell-show-do method. (IRCT.ir IRCT20190720044281N1)

Citation: Tahersoltani A, Heidari A, Ghadimi S, Shamshiri AR (2021) Effect of the Tiny Dentist game on 4-10 years old children's anxiety compared with Tell-ShowDo method: A clinical trial. J Dent Probl Solut 8(1): 034-041. DOI: https://dx.doi.org/10.17352/2394-8418.000102 


\section{Introduction}

Dental anxiety is a common phenomenon in the current era. Regardless of high costs for the healthcare system, it can cause several adverse effects and disorders in patients before, during, or after treatment procedures [1-6]. We can assort these effects based on when they occur, as below:

1. Before treatment: The fear of dental procedures can cause avoidance from attending to the clinic that can lead to a disruption in periodic visits and, after that, a lack of information about people's health conditions. Also, It can cause damage to society's general oral hygiene and health $[7,8]$.

2. During treatment: Dental anxiety during visiting and presence in clinic, or operation, can have unwanted consequences, including uncontrollable behavior, lack of cooperation, tooth pain increase, and adverse psychological effects for patients. The results of these consequences are effective in treatment outcome $[6,9]$.

3. After treatment: Fear institutionalization in the patient's psyche has numerous menaces for him, the clinician, and the health care system. This fear affects various aspects of people's health, such as mental and physical health negatively. Repetitive avoidance of the checkup sessions or lack of cooperation in the treatment process or Negative psychic effect of treatments can spread to other medical fields that can disrupt the access of the health care system to society's general health and hygiene status $[7,8,10]$.

Dental anxiety is especially significant in children because their response to medical necessity is more complicated than adults, and background factors, including character and parents, have a profound influence on these responses $[1,7]$.

In different societies, dentists believe that pediatric dentistry is one of the most challenging procedures, and various studies confirm it. Researchers have studied several reasons for the creation and amplification of anxiety. They have proved and evaluated all these factors, from socio-economic factors such as culture, economic conditions, environment, and methods of nurture to individual factors like age, gender, heredity and character, family and personal experiences, and clinical environment-related factors including staff's inappropriate behavior, and their role in fear. From all these factors, clinicians can improve and modify their medical experience and professional behavior $[2,4,5]$.

In previous years, AAPD suggested a relatively simple protocol for children's reception, behavior technique, and anxiety control. In the field of behavior management techniques, based on the child's response to the clinic environment, they recommend one of the pharmaceutical or behavioral (nonpharmaceutical) techniques $[9,11]$. Researchers proved that behavioral management techniques like cognitive behavior techniques are more successful in fear and behavior control and fewer side effects than the other techniques [12].
Experts have accepted various behavior management techniques in general and placed the tell-show-do method in general guidelines and protocol of meeting pediatric dentistry patients as the gold standard, From the other methods. In summary, this method includes explaining, showing the function of the equipment used during treatment, and even performing a procedure on a phantom, and it is known as the most common behavior management technique in pediatric dentistry [11]. Albeit scientists have made several studies and modifications on its quality and progress in a way that they developed its subset concepts and assorted it in the subgroup of distraction techniques including active methods, e.g., interactive, simulation, and virtual reality games, and passive methods, e.g., visual and auditory media. However, the active methods are more successful in distraction [13]

Due to advances in technology and communication methods and the generalization of computer tools, including personal computers and smartphones, we can benefit from applications and games to perform the tell-show-do method. Usage of the games for medical purposes results in better communication with children. Researchers showed that the advantages of technology-based interventions, e.g., usage of the application in interaction with patients, include better acceptance of the treatment from patients, facilitation of usage, effect in pain relief, and involving of learning powers and as a result, positive psychological influences on the patient $[3,14,15]$.

Tiny Dentist is a dentistry simulation game, designed by the Fantastoonic group for android and iOS. The game style is Role-Playing. At first, it demonstrates different treatment procedures using tutorials to the child, then enters the playing environment. This designation of the game aims to introduce simple dental procedures to the children. It is free to download and play, and it has a simple graphical user interface that is applicable for children below the school ages since the ESRB (Entertainment Software Rating Board) rated it suitable for all ages. Until 2020, the game had received good points in graphics, control, and gameplay; on Google Play and App Store, the average of the points was more than 4 out of 5 . The child fantastically discovers the general dentistry procedures, using this application. In a way, the game applies the tell-show-do purposes and the anxiety control behavioral methods (Figure 1).

This study is trying to evaluate the effect of the Tiny Dentist game on children's anxiety in comparison with the tell-showdo method.
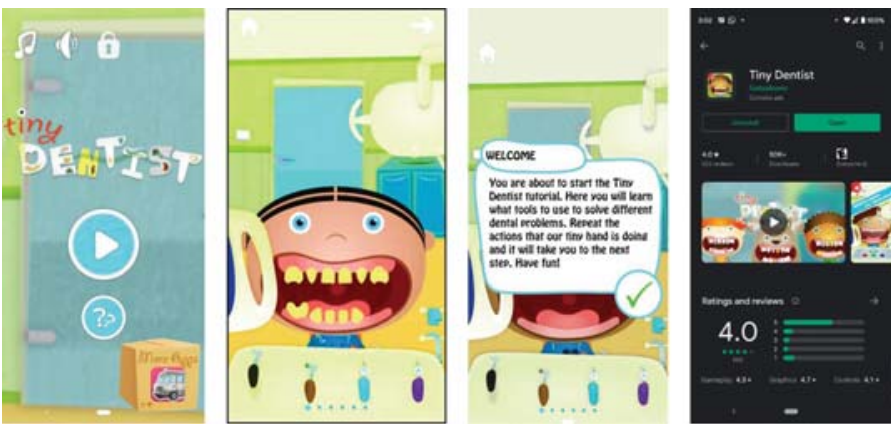

Figure 1: Tiny Dentist. 


\section{Materials and methods}

This study has the ethics license number "IR.TUMS. DENTISTRY.REC.1398.041" from Tehran University of Medical Sciences - School of Dentistry ethics committee and it.is registered on the IRCT (Iranian Registry of Clinical Trials) website with the number "IRCT20190720044281N1".

The patients were accepted within the age range of 4-10 years old. They should not have any dentistry or hospitalization history. Therefore, children with systematic diseases, psychologic and physical disorders, mental and physical retardation, tooth pain in the visit, having a phone or tablet, and history of using the Tiny Dentist app did not participate in the study. To measure the effectiveness of the technique in a specific period, each case lasted more than 60 minutes was omitted from the study. Their treatment plan included hygiene education, infiltration anesthesia, class II filling, or pulpotomy, and SS crown.

The study was a double-blinded (the film evaluators and the analyzer) randomized clinical trial. The simple randomization using the coin-flip method was performed. At first, the clinician in the School of Dentistry, Tehran University of Medical Sciences, gained the necessary information about the application and played its tutorial. She also checked the tellshow-do method process with a professor, followed by patient reception and completing the profile-the rest of the work performed in the absence of the parents.

The clinician introduced herself to the child and guided him/her to the unit. In the beginning, there was not any instrument on the trolley or the unit. The clinician explained to the child that she only wants to examine her mouth and evaluate the condition of his/her teeth, and she does not do anything else. Then the child's heart rate was measured using a pulse-oximeter and noted on the recording paper specified for every patient, and the child was allocated to one of the comparison group or the intervention group by the coin-flip method. The pulse-oximeter was a brand-new Beurer model PO-30, made in Germany. Also, we considered the WongBaker FACES scale for children's pain self-assessment and the Venham 6-points scale for measuring children's anxiety by the professors $[16,17]$

After completing the examination and preserving the treatment plan, the tell-show-do method was performed for the presentation of brushing and class II amalgam filling treatment (in five minutes) for the comparison group. In the intervention group, this progress was accomplished by the application and letting the child play with it for five minutes. Then the pulse-oximeter was attached to the child's left-hand index finger.

The camera was placed in a position that would not get attention before guiding the child to the unit. The child's heart rate was recorded every five minutes during, in the beginning, and at the ending of the procedure.

At last, the Wong-Baker FACES scale was shown to the child and it was asked from him/her to point to the right shape based on the pain he/she encountered during treatment. The duration of treatment was also recorded. The child was asked every 15 minutes to make sure he/she is not hungry, thirsty, exhausted, or having urine or feces, and if anyone was present, the procedure was stopped until resolving the problem.

Two professors who did not know the patient allocation details watched the recorded films and ranked the children's anxiety during treatment by the Venham scale. Also, a psychology professor watched and rated 25 films of all cases with the Venham scale. The Interclass Correlation Coefficients (ICC) of the Venham ratings was calculated for reliability. Based on the guideline, its model was two-way mixed effects, its type was the mean of 3 raters, and its definition was absolute agreement. The calculated value was 0.747 , which indicates a moderate-borderline to good-reliability for the Venham ratings [18].

After gathering the numbers, the data was entered into SPSS version 26. The t-test analysis was used for heart rate and Venham scale variables and the non-parametric MannWhitney analysis was performed for the Wong-Baker index variable. The significant amount of $\mathrm{P}$ was less than 0.05 .

The CONSORT flow diagram of the study is depicted in Figure 2.

\section{Results}

In this study, 143 patients were accepted and treated in total. Seventy-eight were boys, and sixty-five were girls. The randomization method was coin-flipping, so the comparison group included 85, and the intervention group included 58 patients. In terms of age, the average age in the comparison group was $6.16 \pm 1.49$, and in the intervention group was $6.24 \pm 1.58$. Table 1 shows the age and gender distribution of the children in two groups, respectively. Based on this table and Table 2, the age distribution in each group is similar due to the average, the standard deviation, the minimum, and the maximum criteria. To assess the agreement between the professors who watched and scaled the film, the quadratic weighted kappa test was used. The result was 0.41 that indicates relative similarity between their opinion on the Venham scale.

In the following, the independent sample t-test for the studied variables was performed. The variables included the averages of the Venham scale, heart rate before and after the technique, the heart rate before and after injection, the heart rate during treatment, the heart rate difference before and after the technique, and the heart rate difference before and after injection. Table 2 shows the result of the t-test, for each variable.

Due to this table, the p-value is equal to or less than 0.001 in all variables, but the pre-treatment heart rate and the preinjection heart rate that means significance for all but these two variables. Also, the mean difference and $95 \%$ Confidence Interval of the Difference for each variable is in Table 2.

Based on the result of the Mann-Whitney test, the p-value of the Venham scale for the first professor was less than 0.001 and for the second professor was 0.002. Also, the analyzer 


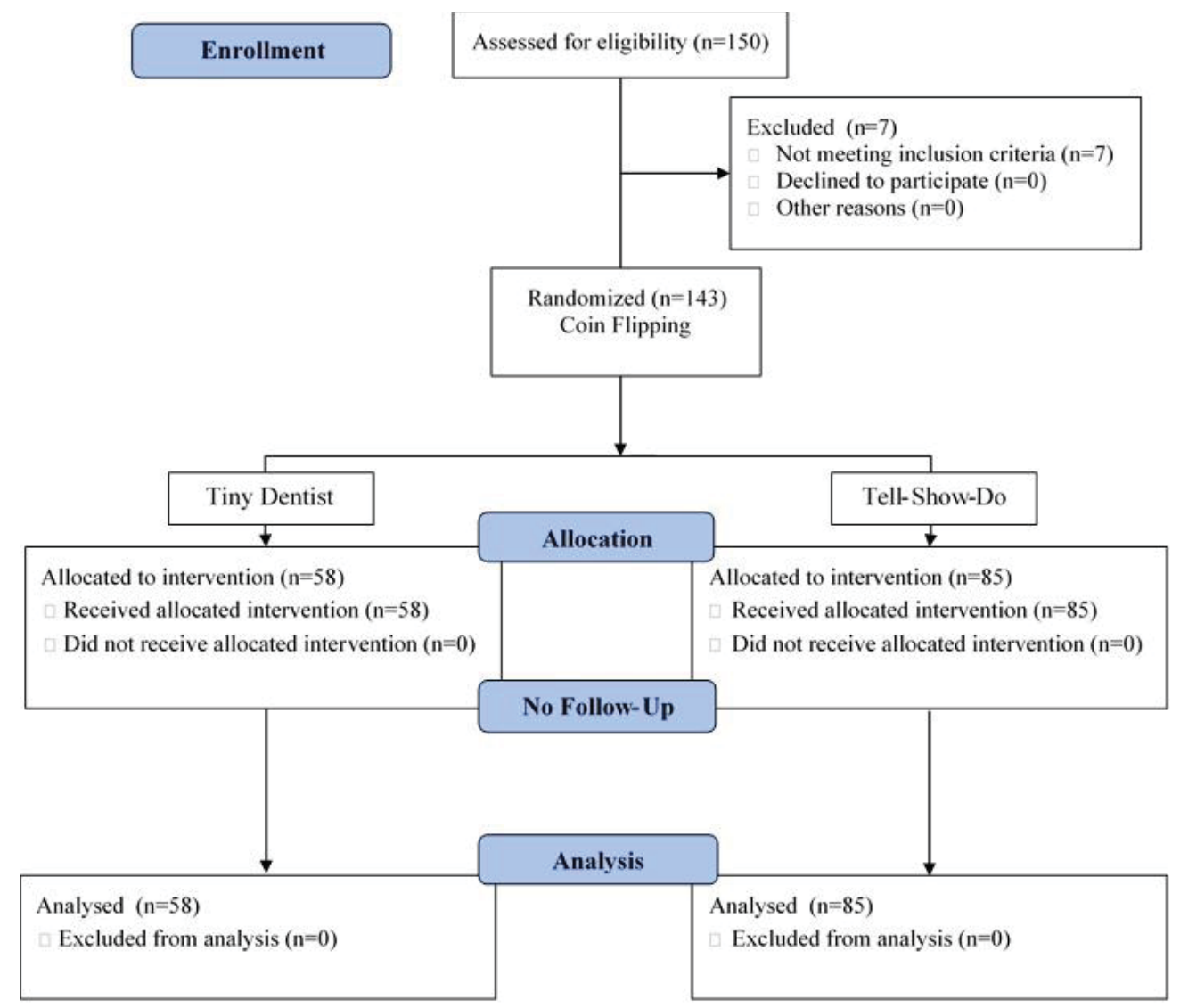

Figure 2: CONSORT Flow diagram.

Table 1: Age and gender distribution of the children in two groups, respectively.

\begin{tabular}{|c|c|c|c|}
\hline & & $\begin{array}{c}\text { Compariso } \\
\text { Group } \\
(\mathrm{n}=85)\end{array}$ & $\begin{array}{c}\text { Intervention } \\
\text { Group } \\
(\mathrm{n}=58)\end{array}$ \\
\hline \multirow{9}{*}{ Age } & Average & 6.16 & 6.24 \\
\hline & Standard Deviation & 1.49 & 1.58 \\
\hline & Maximum & 10 & 9 \\
\hline & Minimum & 4 & 4 \\
\hline & 4 & $10(11.80 \%)$ & $10(17.20 \%)$ \\
\hline & 5 & $23(27.10 \%)$ & $12(20.70 \%)$ \\
\hline & 6 & $19(22.40 \%)$ & $9(15.50 \%)$ \\
\hline & 7 & $18(21.20 \%)$ & $13(22.40 \%)$ \\
\hline & $8-10$ & $15(17.60 \%)$ & $14(24.10 \%)$ \\
\hline \multirow{2}{*}{ Gender } & Boy & $57(67.10 \%)$ & $21(36.20 \%)$ \\
\hline & Girl & $28(32.90 \%)$ & $37(63.80 \%)$ \\
\hline
\end{tabular}

calculated it less than 0.001 for the Wong-Baker index. The grouping variable for this analysis was the type of intervention.

\section{Discussion}

This study has attended to compare the standard method, which is the tell-show-do, with the video game method, in terms of anxiety and pain control. Regarding the age feature, the range of 4 to 10 years old was considered. This range includes both 4 to 6 years and 7 to 10 years old. Studies indicate that the children show the most violent behaviors in the range of 4 to 6 , and they are challenging to control [19]. The range of 7 to 10 includes three first years of elementary school. The patient's characteristic aspects can affect dental anxiety as trait anxiety, and this type of anxiety refers to the patient's characteristic aspects [20]. Also, studies indicate that patients with severe trait anxiety show more anguish in the clinic [21,22], and their responses to anxiety control techniques are weaker than the others [23].

In this study, we used both objective variables, e.g., heart rate, and objective variables, e.g., the Venham scale to assess the pain, the anxiety, and the cooperation from the thirdperson view. Various similar studies had used these variables before, although they achieved discordant results $[6,7,24-26]$.

Before we conclude the collected data and findings from statistical analysis, we need to evaluate the study in terms of various features and its design and compare it with the other similar studies. To interpret the findings of the present study, we have to discuss the data variations divided into different recorded periods and analyze these variations. Therefore, we compare these data in comparison and intervention groups and show how the video game method is effective in children's pain and anxiety control rather than the conventional tell-show-do method.

We categorize the collected data into three subgroups due to the time of recording:

1. Heart rate, which was recorded in different periods and every five minutes during treatment, and categorized into five states; pre-technique, post-technique, 
Table 2: Result of the t-test, for each variable.

\begin{tabular}{|c|c|c|c|c|c|c|}
\hline Variable & Group & Average & Standard Deviation & Mean Difference & 95\%Confidence Interval & p-Value \\
\hline \multirow{2}{*}{ Mean Venham Scale } & Comparison & 1.98 & 1.04 & \multirow{2}{*}{0.73} & \multirow{2}{*}{$0.42-1.05$} & \multirow{2}{*}{$<0.001$} \\
\hline & Intervention & 1.25 & 0.74 & & & \\
\hline \multirow{2}{*}{ Pre-technique Heart rate (bps) } & Comparison & 98.33 & 20.75 & \multirow{2}{*}{-5.07} & \multirow{2}{*}{$-10.49-0.36$} & \multirow{2}{*}{0.07} \\
\hline & Intervention & 103.40 & 11.95 & & & \\
\hline \multirow{2}{*}{ Post-technique Heart rate (bps) } & Comparison & 98.80 & 19.43 & \multirow{2}{*}{11.83} & \multirow{2}{*}{$5.65-18.02$} & \multirow{2}{*}{$<0.001$} \\
\hline & Intervention & 86.97 & 16.72 & & & \\
\hline \multirow{2}{*}{ Pre-injection Heart rate (bps) } & Comparison & 94.87 & 18.41 & \multirow{2}{*}{-4.65} & \multirow{2}{*}{$-10.37-1.07$} & \multirow{2}{*}{0.11} \\
\hline & Intervention & 99.52 & 14.63 & & & \\
\hline \multirow{2}{*}{ Post-injection Heart rate (bps) } & Comparison & 117.11 & 12.08 & \multirow{2}{*}{10.33} & \multirow{2}{*}{$5.48-15.18$} & \multirow{2}{*}{$<0.001$} \\
\hline & Intervention & 106.78 & 15.72 & & & \\
\hline \multirow{2}{*}{ Mean Heart rate During Treatment (bps) } & Comparison & 111.35 & 13.15 & \multirow{2}{*}{6.13} & \multirow{2}{*}{$2.59-9.66$} & \multirow{2}{*}{0.001} \\
\hline & Intervention & 105.22 & 8.22 & & & \\
\hline \multirow{2}{*}{ Heart rate Difference in the intervention phase(bps) } & Comparison & 0.47 & 23.58 & \multirow{2}{*}{16.90} & \multirow{2}{*}{$9.42-24.38$} & \multirow{2}{*}{$<0.001$} \\
\hline & Intervention & -16.43 & 20.06 & & & \\
\hline \multirow{2}{*}{ Heart rate Difference in the injection phase(bps) } & Comparison & 22.24 & 18.05 & \multirow{2}{*}{14.98} & \multirow{2}{*}{$8.93-21.03$} & \multirow{2}{*}{$<0.001$} \\
\hline & Intervention & 7.26 & 17.86 & & & \\
\hline
\end{tabular}

pre-injection, post-injection, and the average of all recorded heart rates during treatment, aiming to unify the samples. Then the samples were analyzed with the t-test.

2. Child's response to the Wong-Baker facial scale, which is an ordinal scale. The Mann-Whitney analysis was used for the data.

3. Professors' assessment with the Venham scale. the average of both professors' marks was considered for each sample.

\section{Anxiety assessment}

Heart rate: Heart rate is a reliable variable for monitoring anxiety condition that several studies have used it. In the present study, we have measured this variable in several periods and calculated the average of them aiming for a total evaluation of their variations during treatment. According to Figure 1, the average of this pre-technique in the comparison group is less than the average in the intervention group. However, due to the similar sample conditions in both groups, there is not any specific reason for that. The amount of the variable increases in the comparison group, while this amount decreases in the intervention group (Figure 3). We can make various reasons for this process. One of the reasons is that playing the game leads to endorphin secretion that improves the child's morale and prepares him/her for a fight-or-flight state; the child gets to know the treatment progress, performs the treatment on a virtual patient himself, becomes able to imagine himself/ herself in the treatment procedure; and therefore, several known factors for anxiety formation, fade out or eliminate.

Anesthesia injection operation is inevitable in invasive dental procedures, and the pain of it is an important factor in patient anxiety increment apart from being a child or an adult, so in the pre-injection period, the heart rate decreases in the comparison group but this variable increases in the intervention group and even it becomes more than the preinjection heart rate in the other group. One probable reason for this consequence is that in the game environment, the child cannot discover any experience of injection, and he/she

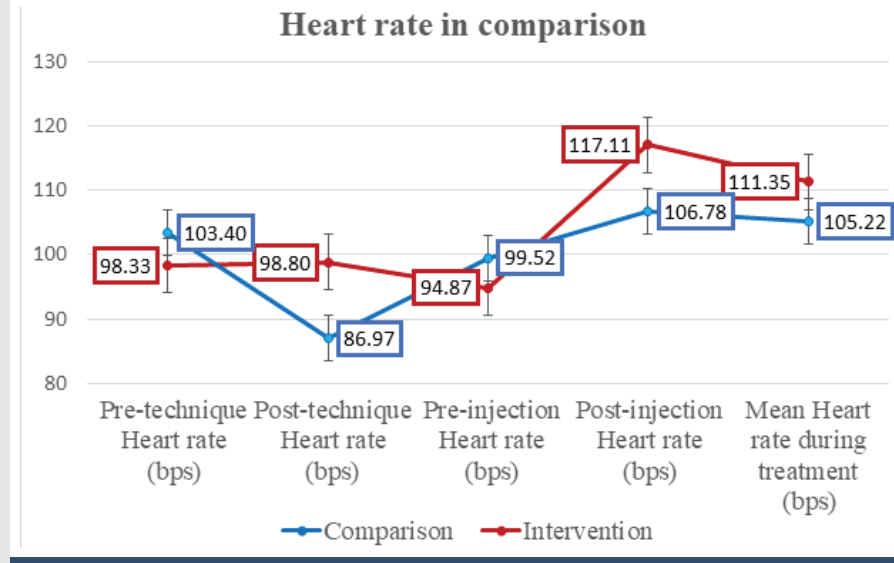

Figure 3: The trend of heart rate changes in 4-10 years old children of the comparison (tell-show-do) group and the intervention (Tiny Dentist game) group.

imagines that dental procedure is not painful for him/her even in a small amount; so he/she does not prepare himself/herself for the experience of injection. On the opposite, perhaps his/ her experience helps him/her control the anxiety during and after injection, so we have less heart rate increment in the intervention group than in the comparison group (Figure 3); in a way that the amount of this variable is significantly less in the intervention group than in the comparison group. At last, the mean heart rate amount has relative stability for both groups during treatment, and it is still less in the intervention group (Figure 4).

Fernandes, et al. evaluated the effect of an educational multimedia application on children's preparation for outpatient surgeries. They divided children into three groups of educational application, an ordinary entertaining game, and no intervention (comparison). The results showed that children in the application group had less anxiety during the operation. They used SAM (Manikin's self-assessment test, aiming the assessment of emotion - arousal and capacity) and two objective variables; heart rate and blood pressure (physiologic response assessment) for monitoring children's conditions, and this might be a positive point for the study. Based on the conclusion, they failed to evaluate the quality of the intervention effects on the patient's emotional states due to the 


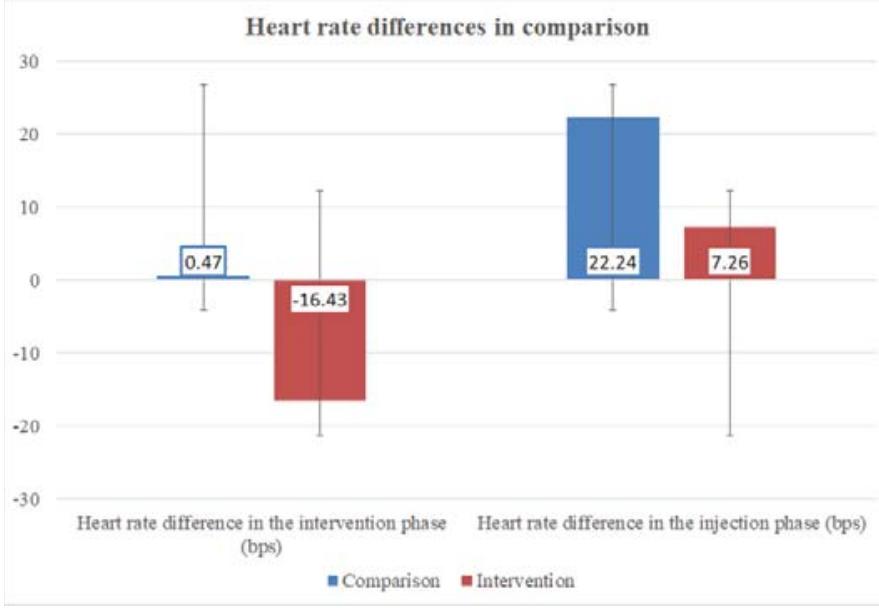

Figure 4: Heart rate differences comparison in the comparison (tell-show-do) group and the intervention (Tiny Dentist game) group.

insignificancy of the data. However, they succeeded in showing the effect of this specific intervention on children's cognitive aspects of the situation. One proposed plausible reason is that the responsible corporation designed the application in a way that only affected the cognitive aspects of the children's psyche and was ineffective in the emotional aspects [25].

Meshki, et al. evaluated the effect of a dental application on anxiety and pain, which was the most similar study to the present study. The sample group contained 50 children. The intervention group had played the game for two weeks until the treatment session. The results showed that playing the game caused anxiety decrement in the treatment session. The independent variables were the heart rate and the WongBaker facial scale, and they measured the heart rate six times only. The study has assessed the long-term effects of playing the game on the child's psyche compared with the standard method, but not its immediate effect in the treatment session. Also, they could have achieved more precise and reliable results if they raised the sample. Therefore, it is clear that persistent working with the game help with the child's orientation to the treatment [27].

Venham scale: Based on the definition, the scale evaluates the child's overall anxiety and cooperation through the external observer's view. It also helps the study to deliberate the results. According to the data from Table 2, the average of the given marks is 1.98 for the comparison group, and 1.25 for the intervention group. The finding indicates that the game technique performed better than the conventional technique in the behavioral guidance and the cooperation attract. Also, according to Table 3, the children with scores 0 and 1 (calm, happy - upset, concerned) are $33.3 \%$ in boys and $50 \%$ in girls in the comparison group, while they consist $61.9 \%$ of the boys and $72.9 \%$ of the girls in the intervention group. Therefore, the intervention group looks calmer and more cooperative and has less anxiety than the comparison group, from the external observers' view.

Paryab, et al. evaluated the filmed modeling method, and they chose the age range of 4 to 6 . In this study, they measured the anxiety and the cooperation with the heart rate, Venham, and Frankel scales. The findings did not show a significant difference between the tell-show-do method and watching the film. Therefore, based on the study, there is no difference between the two methods in children's anxiety decrement. However, the preferred age range is narrow, so maybe we cannot extend the conclusion to the other ages [28].

Vidyavathi, et al. performed a pilot study. They considered 60 children, asked them to play a game, and measured their anxiety and attitude before and after playing the game. The study was successful in illustrating the game's impact on anxiety but failed to represent the amount of it in different conditions [29].

Wong-Baker FACES scale: According to Table 3, in the comparison group, totally $50.9 \%$ of boys and $42.9 \%$ of girls have chosen the first and the second pictures (happy and pleased, respectively), while in the intervention group, the rate is $90 \%$ for boys and $94.6 \%$ for girls. It indicates that the children in the intervention group feel less pain and are more satisfied with their treatment. On the other hand, the rate of the last picture (crying) children chose was $7 \%$ of boys and $3.6 \%$ of girls in the comparison group, but zero for both genders in the intervention group. The fact shows us that fewer children experience pain or unsatisfied with their treatment in the intervention group.

Aminabadi, et al. studied a clinical trial that evaluated the effect of the virtual reality distraction tool on children's pain and anxiety during treatment. They divided 120 children, in the range of 4 to 6 years old without a history of anxiety disorder into two 60 groups. After three sessions of selective treatment that they performed the intervention through a virtual reality eyeglass on the intervention group in the second session, they measured their anxiety using the Wong-Baker facial index and the modified child dental anxiety scale. At last, they observe sensible degrade in pain and anxiety in the intervention group with the intended method. One of the tips they pointed out in this study is that the number of treatment sessions is influential in the findings [30].

Matthyssens, et al. have appraised the proficiency of a medical simulation game in the decrement of the children's pain and anxiety. The study had measured the amount of pain and anxiety with the Visual Analogue Scale (VAS). They entered 167 between the ages of 5 to 11 years old that participated in outpatient surgeries in different medical fields, from general surgery to urology and dentistry. They divided them into three groups of the game, conventional technique (e.g., tell-showdo in the field of dentistry) and no technique. Albeit 69 patients at the beginning of the study and 27 during the study exited. The study declares that the criteria were not sensitive enough to recognize a relative decrement in the amount of pain and anxiety. Also, about the comparison, the difference between the groups with a technique and the group with no technique is sensible, but it shows no difference between the two techniques [31].

\section{Limitations}

One of the limits that exist in our study is that we performed this study in the faculty clinic that is very crowded during the 
Table 3: Children with scores 0 and 1 (calm, happy - upset, concerned).

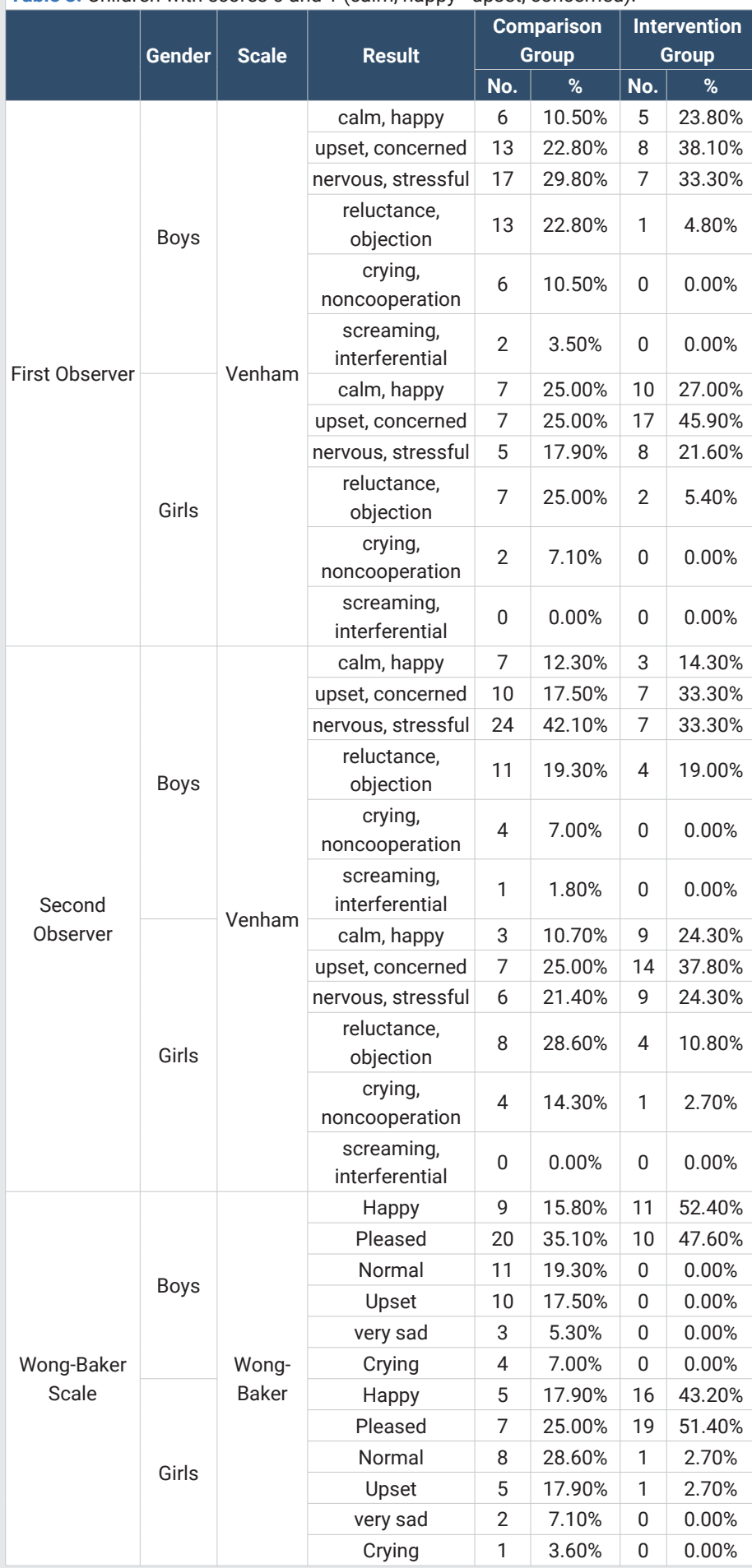

day, and there were several units placed beside each other, so there were numerous child patients at the time. Therefore, environmental factors, e.g., overcrowding, loud noises of the treatments, or the other patients' screaming and crying, may have amplified the fear and anxiety in the child and induced the bias effects in the study. The other limitation is the duration of the treatment that is different in person due to the type of treatment. Although we considered the heart rate average as a variable and assessed it but in one way or another, the pain threshold reduces with the time pass and anesthesia fading. One other limit is that the study happened in the morning, so it is not clear whether the results would be the same in the other times of the day. In the daytime, the blood concentration of the cortisol is high that causes positive in the patient's manner and, consequently, better behavior, cooperation, and less anxiety [32]. The other limitation is that the intervention group size is fewer than the comparison group size that happened because of the coin-flip randomization method. Besides, one another factor that also restricted the study was the avoidance of accepting children with a history of using a tablet or smartphone. The last limitation is that it was the responsibility of one person to record the data and all the indicators along with filming the treatment process, which, despite the scarcity of variables under consideration, made it difficult to measure some variables with accuracy.

\section{Suggestions}

Based on the limitations, we recommend the next studies to have more control over the environmental factors, e.g., noises; also, it is better to consider the treatment durations more controlled to achieve more accurate results. The next studies can apply more scales for the anxiety and cooperation assessment, e.g., the Children's Fear Survey Schedule - Dental Subscale (CFSS-DS), the Frankel scale, the Manikin's SelfAssessment test (SAM), and blood pressure, to improve the accuracy of the study. Matching the data from these variables together and with previous studies, also improves the accuracy. The Improvement requires the subsequent studies held with more involving staff aiming more concentration on each scale. Eventually, we suggest more purposeful studies in more controlled areas with larger samples and more scales to attain more precise results in this field.

\section{Conclusion}

In the present study, we successfully represented the effect of the game method for treatment demonstration rather than the conventional method from the patient, the clinician, and the evaluators' perspective, which is evident from the evaluated variables. These factors have measured the children's pain and anxiety in the treatment session and all confirm the thesis that the Tiny dentist game has acted successfully in children's anxiety decrement and cooperation improvement, in comparison with the conventional method. Therefore, it seems that using a simulation game for treatment demonstration may have enough efficiency rather than the conventional method, or leastwise, as an option beside the standard method in anxious and non-cooperative children.

\section{References}

1. Chhabra N, Chhabra A, Walia G (2012) Prevalence of dental anxiety and fear among five to ten year old children: a behaviour based cross sectional study. Link: https://bit.ly/3mKgqMZ

2. Costa LR, Bendo CB, Daher A, Heidari E, Rocha RS, et al. (2020) A curriculum for behaviour and oral healthcare management for dentally anxious children-Recommendations from the Children Experiencing Dental Anxiety: Collaboration on Research and Education (CEDACORE). Int J Paediatr Dent 30 556-569. Link: https://bit.ly/3mKgsEB

3. Coutinho MB, Damasceno JX, Mesquita Cals de Oliveira PC, Alves Marinho 
IM, Marçal E, et al. (2020) A Novel Mobile App Intervention to Reduce Dental Anxiety in Infant Patients. Telemed J E Health 1-7. Link: https://bit.ly/2QIhL07

4. Klingberg G, Broberg AG (2007) Dental fear/anxiety and dental behaviour management problems in children and adolescents: A review of prevalence and concomitant psychological factors. Int J Paediatr Dent 17: 391-406. Link: https://bit.ly/3gaLVP8

5. Klingberg G, Löfqvist LV, Bjarnason S, Norén JG (1994) Dental behavio management problems in Swedish children. Community Dent Oral Epidemiol 22: 201-205. Link: https://bit.ly/2QqoSER

6. Yon MJY, Chen KJ, Gao SS, Duangthip D, Lo ECM, et al. (2020) An Introduction to Assessing Dental Fear and Anxiety in Children. Healthcare 8: 86. Link: https://bit.ly/3dVPHZS

7. Grisolia BM, dos Santos APP, Dhyppolito IM, Buchanan H, Hill K, et al. (2021) Prevalence of dental anxiety in children and adolescents globally: A systematic review with meta-analyses. Int J Paediatr Dent 31: 168-183. Link: https://bit.ly/32cF5Af

8. Wogelius P, Poulsen S (2005) Associations between dental anxiety, dental treatment due to toothache, and missed dental appointments among six to eight-year-old Danish children: A cross-sectional study. Acta Odontologica Scandinavica 63: 179-182. Link: https://bit.ly/3dVPNRe

9. Kuhn BR, Allen KD (1994) Expanding child behavior management technology in pediatric dentistry: a behavioral science perspective. Pediatr Dent 16: 13-17. Link: https://bit.ly/3wWmG9d

10. Chellappah NK, Vignehsa H, Milgrom P, Lam LG (1990) Prevalence of dental anxiety and fear in children in Singapore. Community Dent Oral Epidemiol 18 269-271. Link: https://bit.ly/3g8JZXf

11. Revision L (2015) AAPD Behavior Guidance. Aapd 266-279.

12. Gomes HS, Viana KA, Batista AC, Costa LR, Hosey MT, et al. (2018) Cognitive behaviour therapy for anxious paediatric dental patients: A systematic review. Int J Paediatr Dent 28: 422-431. Link: https://bit.ly/3dgxfvR

13. Koller D, Goldman RD (2012) Distraction Techniques for Children Undergoing Procedures: A Critical Review of Pediatric Research. J Pediatr Nurs 27: 652681. Link: https://bit.ly/3sihwk0

14. McQueen A, Cress C, Tothy A (2012) Using a tablet computer during pediatric procedures a case series and review of the "apps." Pediatr Emerg Care 28: 712-714. Link: https://bit.ly/3e4Y8Iw

15. Smith K, Iversen C, Kossowsky J, O'Dell S, Gambhir R, et al. (2015) Apple apps for the management of pediatric pain and pain-related stress. Clin Pract Pediatr Psychol 3: 93-107. Link: https://bit.ly/3ddZvzk

16. Venham LL, Gaulin-Kremer E, Munster E, Bengston-Audia D, Cohan J (1980) Interval rating scales for children's dental anxiety and uncooperative behavior. Pediatr Dent 2: 195-202. Link: https://bit.ly/2RA8HWn

17. Wong D, Hockenberry-Eaton M, Focus DWHH (1996) undefined. (n.d.). Wong Baker faces pain rating scale.

18. Koo TK, Li MY (2016) A Guideline of Selecting and Reporting Intraclass Correlation Coefficients for Reliability Research. J Chiropr Med 15: 155-163. Link: https://bit.ly/3dgz0t5

19. Marwah N, Raju O, Prabhakar A (2007) A comparison between audio and audiovisual distraction techniques in managing anxious pediatric dental patients. J Indian Soc Pedod Prev Dent 25: 177. Link: https://bit.ly/3ga9Ca0
20. Muris $P$, Merckelbach $H$, Van Brakel A, Mayer B, Van Dongen L (1998) The screen for child anxiety related emotional disorders (SCARED): Relationship with anxiety and depression in normal children. Pers Individ Dif 24: 451-456. Link: https://bit.ly/3mWzckx

21. Akarslan ZZ, Erten H, Uzun O, Iseri E, Topuz O (2010) Relationship between trait anxiety, dental anxiety and DMFT indexes of Turkish patients attending a dental school clinic. East Mediterr Health J 16: 558-562. Link: https://bit.ly/3tIE1Gf

22. Furman $E$, Roma Jasinewicius $T$, Bissada NF, Victoroff $K Z$, Skillicorn $R$, et al. (2009) Virtual reality distraction for pain control during periodontal scaling and root planing procedures. J Am Dent Assoc 140: 1508-1516. Link: https://bit.ly/3tdsdps

23. Dahlquist LM, Weiss KE, Clendaniel LD, Law EF, Ackerman CS, et al. (2009) Effects of videogame distraction using a virtual reality type head-mounted display helmet on cold pressor pain in children. J Pediatr Psychol 34: 574584. Link: https://bit.ly/2RA3FJq

24. Fernandes S, Arriaga P, Esteves F (2015) Using an Educational Multimedia Application to Prepare Children for Outpatient Surgeries. Health Communication 30: 1190-1200. Link: https://bit.ly/3thKKRn

25. Fernandes SC, Arriaga P, Esteves F (2014) Providing preoperative information for children undergoing surgery: a randomized study testing different types of educational material to reduce children's preoperative worries. Health Educ Res 29: 1058-1076. Link: https://bit.ly/3uQbQQc

26. Shaheen A, Nassar O, Khalaf I, Kridli SAO, Jarrah S, et al. (2018) The effectiveness of age-appropriate pre-operative information session on the anxiety level of school-age children undergoing elective surgery in Jordan. Int J Nurs Pract 24: e12634. Link: https://bit.ly/3dicsYO

27. Meshki R, Basir L, Alidadi F, Behbudi A, Rakhshan V (2018) Effects of Pretreatment Exposure to Dental Practice Using a Smartphone Dental Simulation Game on Children's Pain and Anxiety: A Preliminary Double-Blind Randomized Clinical Trial. Journal of Dentistry (Tehran, Iran) 15: 250-258. Link: https://bit.ly/3shKOdY

28. Paryab M, Arab Z (2014) The effect of Filmed modeling on the anxious and cooperative behavior of $4-6$ years old children during dental treatment: A randomized clinical trial study. Dent Res J 11: 502-507. Link: https://bit.ly/3gcZLQS

29. Patil V, Vaid K, Gokhale N, Shah P, Mundada M, et al. (2017) Evaluation of effectiveness of dental apps in management of child behaviour: A pilot study. International Journal of Pedodontic Rehabilitation 2: 14. Link: https://bit.ly/3tioib2

30. Asl Aminabadi N, Erfanparast L, Sohrabi A, Ghertasi Oskouei S, Naghili A (2012) The Impact of Virtual Reality Distraction on Pain and Anxiety during Dental Treatment in 4-6 Year-Old Children: a Randomized Controlled Clinical Trial. J Dent Res Dent Clin Dent Prospects 6: 117-11724. Link: https://bit.ly/3uMKryu

31. Matthyssens LE, Vanhulle A, Seldenslach L, Vander Stichele G, Coppens $\mathrm{M}$, et al. (2019) A pilot study of the effectiveness of a serious game CliniPup ${ }^{\circledR}$ on perioperative anxiety and pain in children. J Pediatr Surg Link: https://bit.ly/3uPTDSU

32. Wirth MM, Scherer SM, Hoks RM, Abercrombie HC (2011) The effect of cortisol on emotional responses depends on order of cortisol and placebo administration in a within-subject design. Psychoneuroendocrinology 36 945-954. Link: https://bit.ly/3dgzEXx

Copyright: @ 2021 Tahersoltani A, et al. This is an open-access article distributed under the terms of the Creative Commons Attribution License, which permits unrestricted use, distribution, and reproduction in any medium, provided the original author and source are credited.

Citation: Tahersoltani A, Heidari A, Ghadimi S, Shamshiri AR (2021) Effect of the Tiny Dentist game on 4-10 years old children's anxiety compared with Tell-ShowDo method: A clinical trial. J Dent Probl Solut 8(1): 034-041. DOI: https://dx.doi.org/10.17352/2394-8418.000102 